\title{
What to Expect for the New Year?
}

Last year, I finished my editorial with the statement "Enjoy reading our journal and let's work for a wonderful $2020 " .{ }^{1}$ In the year 2020, we certainly enjoyed reading the Journal of the Brazilian Chemical Society (JBCS). We published 12 issues comprising 264 papers and editorials, totalizing over 2,600 pages. We have also worked for a wonderful year, however, since its beginning, we have faced the Covid-19 pandemic and its consequences. Covid-19 started in China in the end of 2019 and very quickly spread out all over the world. Brazil has also suffered with the sanitary impact of this disease and all of us have struggled to mitigate its damages. Science has had an important role on Covid-19, firstly because the solution for this pandemic will come from science through the development of vaccines for prevention, already in place in some countries, and medicines to treat it. On the other hand, countries like Brazil and others have experienced severe impacts on their economies that have negatively reflected on science and technology (S\&T). Brazil has had budget cuts, and it is unfortunate to realize that S\&T is one of the first areas to suffer from a shortage in investments. Despite the problems of 2020, a new year is beginning, and here we are again welcoming all the people involved with the JBCS activities. Before I announce the changes for 2021, I should mention that in the last year we had a moment for reflection on the role and the consequences of racial and gender discriminations in science. The JBCS in a joint publication with journals of the American Chemical Society paid attention to that and published a paper authored by Dr Daniel G. Rivera, the president of the Latin American Federation of Chemical Associations, that appeared in the JBCS as a letter ${ }^{2}$ and was published as an Editorial in the ACS journals Organic Letters, The Journal of Organic Chemistry, Organometallics, and Inorganic Chemistry.

As it happens every year, for 2021, I would like to announce some of the changes we will implement in our editorial team. The first refers to the replacement of the editor of analytical chemistry in which Dr Maria das Graças Andrade Korn from the Federal University of Bahia is taking the position from Dr Edenir Rodrigues Pereira Filho from the Federal University of São Carlos. Also, Dr Roberto M.
Torresi is no longer one of the editors. I would like to welcome the new editor and thank the two editors who are leaving now. Facing difficulties in obtaining financial support from Brazilian funding agencies, in addition to the cost increases of some of our contractors, and to keep the journal running, we have been impelled to rethink the JBCS page charges. The solution found for this matter was not a broad increase but mostly a cut in some benefits previously applied to the members of the Brazilian Chemical Society (SBQ), who had considerable discounts on the page charges, no longer available, at least to the same extent. Needless to say, that all the constraints in the economy caused by the Covid-19 pandemic have negatively impacted on the capacity of the chemistry community to produce high-quality research. This may reflect in the coming years and may generate a situation of decrease in the number of papers submitted for publication in the JBCS. We are aware of that and are welcoming a solution for Covid-19, however we know that damages caused so far will impact on the future. As always, despite the current adversities, the JBCS assures authors of its commitment to the purpose of publishing scientific papers of international relevance and their wide dissemination.

Finally, I should thank the collaboration of authors and reviewers for their support to keep the high standards of the journal. The JBCS and SBQ are very thankful for their work as are thankful for the editors and advisory board who have devoted part of their time to our journal.

I finish this editorial with the same statement of last year: enjoy reading our journal and let's work for a wonderful 2021.

Paulo Cezar Vieira Editor-in-chief of the Journal of the Brazilian Chemical Society Universidade de São Paulo (USP), Ribeirão Preto-SP, Brazil

\section{References}

1. Vieira, P. C.; J. Braz. Chem. Soc. 2020, 31, 1.

2. Rivera, D. G.; J. Braz. Chem. Soc. 2020, 31, 1965. 